\title{
Insights in the treatment of congenital nasolacrimal duct obstruction
}

\author{
Avram Elena \\ Ophthalmology Department, Medlife Băneasa Hyperclinic, Bucharest, Romania
}

Correspondence to: Elena Avram, MD,

Ophthalmology Department, Medlife Băneasa Hyperclinic, Bucharest,

10 București-Ploiești Highway, Code 013693, Bucharest, Romania,

Mobile phone: +40741608 980, E-mail: dr.elena_avram@yahoo.com

Accepted: May 27th, 2017

\begin{abstract}
Introduction: Congenital nasolacrimal duct obstruction is one of the most common causes of epiphora in newborns and the main cause of this condition is the persistence of Hasner membrane. Several treatment options are available, like conservative treatment, probing, irrigation, or more complex techniques.

Objective: The objective of this paper is to discuss the efficiency of different treatment options addressing congenital nasolacrimal duct obstruction based on trials reported in literature.

Methods: Clinical trials were identified on PubMed. The results were discussed regarding patient age, type of treatment and efficiency of the treatment.

Results: 41 trials were reviewed. The rate of resolution according to different treatment options was the following: conservative treatment 14.2-96\%, probing 78-100\%, irrigation $33-100 \%$, silicon tube intubation $62-100 \%$, inferior turbinate fracture 54.7$97 \%$, balloon dacryocystoplasty 77\%, endoscopic intranasal surgery $92.72 \%$, and dacryocystorhinostomy 88.2-93.33\%.

Conclusions: The first choice in uncomplicated cases should be a conservative treatment, which can be followed until the age of 1 year, while in complicated cases other solutions should be considered.

Keywords: congenital nasolacrimal duct obstruction, probing, dacryocystorhinostomy Abbreviations: $\mathrm{CNDO}=$ Congenital nasolacrimal duct obstruction, $\mathrm{DCR}=$ Dacryocystorhinostomy, $\mathrm{MCI}=$ Monocanalicular intubation, $\mathrm{BCI}=$ Bicanalicular intubation
\end{abstract}

\section{Introduction}

In the management of congenital nasolacrimal duct obstruction (CNDO), very complex and noninvasive treatment options can be used: conservative treatment, probing, irrigation, silicon tube intubation, inferior turbinate fracture, balloon dacryocystoplasty, endoscopic intranasal surgery, or dacryocystorhinostomy. It is important that the technique we choose to be in correlation with the etiology of the disease and the complexity of the case.

\section{Objective}

The objective of this paper was to analyze the efficiency of different treatment options 
addressing CNDO, based on trials reported in literature.

\section{Methods}

Clinical trials were identified on PubMed. The results were discussed regarding patient age, type of treatment and efficiency of treatment.

\section{Results}

- Conservative treatment

At present, the current trend is to indicate a conservative treatment and expect spontaneous remission of CNDO. Conservative treatment entails: lacrimal sac compression and massage, rigorous hygiene of the eyelids and, if there is any purulent discharge, antibiotic eye drops (netilmicin). It is generally recommended up to the age of 12 months and then, depending on the severity of the symptoms, other therapeutic options can be discussed. The success rate is between $14.2 \%$ and $96 \%$ depending on the patients' age (Table 1). It seems that compliance to treatment is a key factor. Karti compared two groups, one in which parents regularly applied lacrimal sac massage with a remission of $92.2 \%$ and another group with parents who did not regularly apply lacrimal sac massage, with a success rate of $77.7 \%$ of the cases [3].

Table 1. Success rate of conservative treatment during the first 12 months of life $[\mathbf{1 , 2}]$

\section{Patient age}

1 month

2 months

3 months

4 months

5 months

6 months

7 months

8 months

9 months

10 months

11 months
Kakizaki H

(2008)

$82.9 \%$

$82.4 \%$

$80 \%$

$79.3 \%$

$76 \%$

$68.4 \%$

$66.7 \%$

$64.7 \%$

$57.1 \%$

$33.3 \%$

$14.2 \%$
PEDIG

(2012)

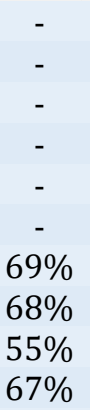

\section{- Probing}

This method has long been considered the first choice treatment in CNDO and it can be performed under local anesthesia before the age of 4-6 months or under general anesthesia $[4,5]$.

The right moment of probing remains controversial, the main problem being the possibility of spontaneous resolution during the first 12 months of life. However, it is advisable to be performed before the age of 12 months if complications appear.

Some physicians prefer to approach the nasolacrimal duct from the upper punctum while others from the lower punctum or from both sides. The punctum is dilated. The probe is introduced vertically. The lid is pulled laterally and the probe is advanced horizontally until it reaches the nasal wall of the lacrimal sac. The lateral traction is released and the probe is turned 90 degrees and directed downward, posteriorly and laterally.

There are several probing techniques:

- Probing guided with soft cannula which implies that a plastic intravenous catheter sheath is supported intraluminal with a guiding metal probe and has a success rate of $89.8 \%$ [6];

- Probing with manually bent Bowman probes that mimic the natural curve of the nasolacrimal duct have a success rate of $91.4 \%$, while straight Bowman probes have a success rate of $76.2 \%$ [7];

- Endoscopic assisted probing allows a direct visualization of the nasolacrimal duct and avoids the formation of false routes, its efficiency varying between $92.3 \%$ and $100 \%$ [8-10].

Success rate of probing varies between 78 and $100 \%$ (Table 2) and decreases with the age of the patient. Takahashi showed that the 
success rate in the second probing is lower than in the first [14].

Main side effects of this therapeutic approach are creating false routes and

Table 2. Success rate after probing $[\mathbf{4 , 5 , 1 1 - 1 3}]$

\begin{tabular}{|c|c|}
\hline & Patients' age \\
\hline \multirow{5}{*}{$\begin{array}{l}\text { Abrishami M } \\
\text { (2009) }\end{array}$} & $15-24$ months \\
\hline & $25-36$ months \\
\hline & $37-48$ months \\
\hline & $49-60$ months \\
\hline & $>60$ months \\
\hline \multirow{2}{*}{$\begin{array}{l}\text { Arora S } \\
(2012)\end{array}$} & $<36$ months \\
\hline & $>36$ months \\
\hline \multirow{5}{*}{$\begin{array}{l}\text { Rajabi MT } \\
(2014)\end{array}$} & $24-36$ months \\
\hline & $37-48$ months \\
\hline & $49-60$ months \\
\hline & $<6$ months \\
\hline & $6-11$ months \\
\hline \multirow{4}{*}{$\begin{array}{l}\text { Hung CH } \\
\text { (2015) }\end{array}$} & $12-17$ months \\
\hline & $18-23$ months \\
\hline & $24-35$ months \\
\hline & $36-60$ months \\
\hline $\begin{array}{l}\text { Le Garrec J } \\
(2016)\end{array}$ & $<12$ months \\
\hline \multicolumn{2}{|c|}{$\begin{array}{l}100 \% \text { according to various authors, involves } \\
\text { injecting saline solution with or without } \\
\text { antibiotic in the lacrimal pathways and is } \\
\text { considered less invasive than probing. It can } \\
\text { affect the tear ducts epithelium and can lead to } \\
\text { the pulmonary aspiration of the fluids used } \\
{[\mathbf{1 5 , 1 6 ] .}}\end{array}$} \\
\hline
\end{tabular}

\section{- Silicon tube intubation}

Lacrimal pathways prosthesis with silicone tubes is indicated in ineffective conservative treatment, failed probing, or presence of strictures.

There are two main types of silicone tubes used: monocanalicular (Mono Crawford, Monoka, Masterka) and bicanalicular (Crawford, Bika, Infant - Bika, Goldberg, Ritleng) and it is recommended that this invasive maneuver is performed under endoscopic control.

According to various authors, the success rate is between $62 \%$ and $100 \%$ [17-26]. Also Kassif showed that the rate of spontaneous resolution after unsuccessful intubation with silicone tube is $80 \%$ [26]. epithelium damage due to scarring strictures tear.

$\begin{array}{ll}\text { Success rate } & \text { Type of anesthesia } \\ 76 \% & \\ 67.7 \% & \text { general } \\ 90 \% & \\ 60 \% & \\ 75 \% & \\ 78 \% & \text { general } \\ 50 \% & \\ 85 \% & \text { general } \\ 63 \% & \\ 50 \% & \\ 90.1 \% & \\ 79.6 \% & \\ 76.8 \% & \text { topical } \\ 73.5 \% & \\ 75 \% & \\ 33 \% & \text { topical } \\ 76.7 \% & \end{array}$

Several studies in which monocanalicular intubation (MCI) with bicanalicular intubation (BCI) results were compared were published. Some scientists like Rajabi showed that BCI is more effective while others, like Lee or Komínek, did not find a significant difference between the two groups $[\mathbf{1 9 , 2 3 , 2 4 ]}$. Also regarding MCI, Andalib and Rajabi reported better results with Monoka stent than with Masterka stent $[\mathbf{2 4 , 2 5 ]}$.

Complications encountered are: symptoms relapse due to premature removal, atony of lacrimal punctum, corneal erosions, displacement, injury to the nasal mucosa and lower cone during the recovery procedure of the dislodged silicone tube [17-26].

\section{- Inferior turbinate fracture}

The use of inferior turbinate fracture usually associated with probing is recommended when there is a narrow space around the nasolacrimal duct ostium.

This technique has a controversial efficiency. Ab. Attarzadeh and Katowitz did not found a high rate of success while Havins reported no failure when applying inferior nasal conchae fracture [27-29]. 


\section{- Balloon dacryocystoplasty}

Dilatation with balloon catheter or balloon dacryocystoplasty is performed by inserting a guide wire with a deflated balloon attached through the punctum in the nasolacrimal duct. The balloon is gently inflated with liquid and the pressure created opens up and expands the blocked duct. The balloon is deflated and removed. The success rate is $77 \%$ [30].

$\mathrm{Hu}$ compared balloon catheter dilatation with silicon intubation after a failed probing and obtained a $64.7 \%$ remission rate in the first group and an $86.1 \%$ remission rate in the second group [31]. This method is beginning to be proposed as an alternative to silicone tube intubation, having a lower rate of complications like epistaxis and lacrimal duct laceration [32].

\section{- Endoscopic intranasal surgery}

Proposed by Korkmaz, this new technique consists in an endoscope-guided inspection of the Hasner valve area, irrigation, incision of the imperforate Hasner membrane valve and again irrigation. The success rate is $92.72 \%$ [33].

\section{- Dacryocystorhinostomy}

Dacryocystorhinostomy (DCR) involves creating an anastomosis between the lacrimal sac and the nasal mucosa by means of a localized bone resection of the nose wing. It represents the last resort when other therapeutic methods have failed.

There are two types of DCR, external and internal (endonasal/ endoscopic). The success rate of the two surgical approaches in children is relatively the same (Table 3 ). Choung indicated that combining DCR with silicone tube intubation prevents failure, while Pakdel showed that this technique is not superior $[\mathbf{3 8 , 3 9 ]}$.

Kamal published a study in which he applied circumostial Mitomicin C during external and endoscopic DCR with an anatomical success rate of $97.3 \%$ and a functional success rate of $96.4 \%[40]$.

Table 3. Success rate of internal and external DCR [34-37]

\begin{tabular}{|c|c|c|}
\cline { 2 - 3 } \multicolumn{1}{c|}{} & \multicolumn{2}{c|}{ Success rate } \\
\cline { 2 - 3 } \multicolumn{1}{c|}{} & External DCR & Internal DCR \\
\hline $\begin{array}{c}\text { Hartikainen J } \\
\text { (1998) }\end{array}$ & $89.1 \%$ & $90.2 \%$ \\
\hline Cokkeser Y & $88.2 \%$ & $89.2 \%$ \\
\hline
\end{tabular}

\begin{tabular}{|c|c|c|}
\hline $\mathbf{( 2 0 0 0 )}$ & & \\
\hline Vivek KP (2013) & $90 \%$ & $86.67 \%$ \\
\hline Dey AK (2014) & $93.33 \%$ & $90 \%$ \\
\hline
\end{tabular}

\section{Conclusions}

During the last years, many trials regarding congenital nasolacrimal duct obstruction have been published, making it possible to conclude that the first treatment choice in uncomplicated cases should be a conservative treatment which can be applied until the age of 1 year. In complicated cases, a complex management should be taken into consideration.

In the last years, new techniques have been developed and classic techniques have been improved, which enhances the outcome of CNDO.

\section{Disclosure}

None.

\section{References}

1. Kakizaki H, Takahashi Y, Kinoshita S, Shiraki K, Iwaki M. The rate of symptomatic improvement of congenital nasolacrimal duct obstruction in Japanese infants treated with conservative management during the 1st year of age. Clinical Ophthalmology. 2008; 2(2):291-294.

2. Pediatric Eye Disease Investigator Group. Resolution of Congenital Nasolacrimal Duct Obstruction with Nonsurgical Management. Archives of Ophthalmology. 2012;

doi:10.1001/archophthalmol.2012.454. 130(6):730-734.

3. Karti O, Karahan E, Acan D, Kusbeci T. The natural process of congenital nasolacrimal duct obstruction and effect of lacrimal sac massage. Int Ophthalmol. 2016; 36(6):845-849. doi: 10.1007/s10792-016-02085.

4. Le Garrec J, Abadie-Koebele C, Parienti JJ, Molgat Y, Degoumois A, Mouriaux F. Nasolacrimal duct office probing in children under the age of 12 months: Cure rate and cost evaluation. J Fr Ophtalmol. 2016; 39(2):171-7. doi: 10.1016/j.jfo.2015.06.009.

5. Hung CH, Chen YC, Lin SL, Chen WL. Nasolacrimal Duct Probing under Topical Anesthesia for Congenital Nasolacrimal Duct Obstruction in Taiwan. Pediatr Neonatol. 2015; 56(6):402-7. doi: 10.1016/j.pedneo.2015.04.001.

6. Yuksel D, Ozer PA. Long-term results of probing guided with soft cannula in children with congenital nasolacrimal ductobstruction. Jpn J Ophthalmol. 2014; 58(1):94-9. doi: 10.1007/s10384-013-0289-x.

7. Serin D, Buttanri IB, Sevim MS, Buttanri B. Primary probing for congenital nasolacrimal duct obstruction with manually curved Bowman probes. Clinical 
Ophthalmology (Auckland, NZ). 2013; 7:109-112. doi:10.2147/OPTH.S39926.

8. Theodoropoulou S, Sutherland MS, Haddow K, Blaikie A. Success rates of endoscopic-assisted probing for congenital nasolacrimal duct obstruction in children. J Laryngol Otol. 2013; 127(8):794-8. doi: 10.1017/S0022215113001370.

9. Sasaki H, Takano T, Murakami A. Direct endoscopic probing for congenital lacrimal duct obstruction. Clin Exp Ophthalmol. 2013; 41(8):729-34. doi: 10.1111/ceo.12108.

10. Fujimoto M, Ogino $\mathrm{K}$, Matsuyama $\mathrm{H}$, Miyazaki $\mathrm{C}$. Success rates of dacryoendoscopy-guided probing for recalcitrant congenital nasolacrimal ductobstruction. Jpn J Ophthalmol. 2016; 60(4):274-9. doi: 10.1007/s10384-016-0445-1.

11. Abrishami M, Bagheri A, Salour S-H, Mirdehghan SA. Late Probing for Congenital Nasolacrimal Duct Obstruction. Journal of Ophthalmic \& Vision Research. 2009; 4(2):102-104.

12. Arora S, Koushan K, Harvey JT. Success rates of primary probing for congenital nasolacrimal obstruction in children. J AAPOS. 2012; 16(2):173-6. doi: 10.1016/j.jaapos.2011.12.151.

13. Rajabi MT, Abrishami Y, Hosseini SS, Tabatabaee SZ, Rajabi MB, Hurwitz JJ. Success rate of late primary probing in congenital nasolacrimal duct obstruction. J Pediatr Ophthalmol Strabismus. 2014 Nov-Dec; 51(6):360-2. doi: 10.3928/01913913-20140909-02.

14. Takahashi Y, Kakizaki H, Chan WO, Selva D. Management of congenital nasolacrimal duct obstruction. Acta Ophthalmol. 2010 Aug; 88(5):50613. doi: 10.1111/j.1755-3768.2009.01592.x.

15. Marr JE, Drake-Lee A, Willshaw HE. Management of childhood epiphora. Br J Ophthalmol. 2005; 89:11231126. doi:10.1136/bjo.2005.069286.

16. Casady DR, Douglas RMD, Meyer Dale RMD, Simon John WMD, Stasior George OMD, Zobal-Ratner Jitka LMD. Stepwise treatment paradigm for congenital nasolacrimal duct obstruction. Ophthal. Plas. Reconstr. Surg. 2006; 22:243-7. doi: 10.1097/01.iop.0000225750.25592.7f.

17. Lim CS, Martin F, Beckenham T, Cumming RG. Nasolacrimal duct obstruction in children: outcome of intubation. J. AAPOS. 2004; 8:466-472.

18. Peterson NJ, Weaver RG, Yeatts RP. Effect of shortduration silicone intubation in congenital nasolacrimal duct obstruction. Ophthal. Plast. Reconstr. Surg. 2008; 24:167-171.

19. Komínek P, Cervenka S, Matousek P. Does the length of intubation affect the success of treatment for congenital nasolacrimal duct obstruction?. Ophthal. Plast. Reconstr. Surg. 2010; 26(2):103-5. doi: 10.1097/IOP.0b013e3181b8e0aa.

20. Memon MN, Siddiqui SN, Arshad M, Altaf S. Nasolacrimal duct obstruction in children: outcome of primary intubation. J. Pak. Med. Assoc. 2012; 62(12):1329-32.

21. Fayet B, Katowitz WR, Racy E, Ruban JM, Katowitz JA. Pushed monocanalicular intubation: an alternative stenting system for the management of congenital nasolacrimal duct obstructions. J. AAPOS. 2012; 16(5):468-72. doi: 10.1016/j.jaapos.2012.07.003.
22. Yu G, Hu M, Wu Q, Cao WH, Fan YW, Lin Q, Liu W. Factors affected therapeutic results in treatment of children congenital nasolacrimal duct obstruction by Ritleng lacrimal intubation. Zhonghua Yan Ke Za Zhi. 2012; 48(5):423-7.

23. Lee H, Ahn J, Lee JM, Park M, Baek S. Clinical effectiveness of monocanalicular and bicanalicular silicone intubation for congenital nasolacrimal duct obstruction. J. Craniofac. Surg. 2012; 23(4):1010-4. doi: 10.1097/SCS.0b013e31824dfc8a.

24. Rajabi MT, Zavarzadeh N, Mahmoudi A et al. Bicanalicular versus monocanalicular intubation after failed probing in congenital nasolacrimal duct obstruction. International Journal of Ophthalmology. 2016; 9(10):1466-1470. doi:10.18240/ijo.2016.10.16.

25. Andalib D, Mansoori H. A comparison between monocanalicular and pushed monocanalicular silicone intubation in the treatment of congenital nasolacrimal duct obstruction. International Journal of Ophthalmology. 2014; $\quad 7(6): 1039-1042$. doi:10.3980/j.issn.2222-3959.2014.06.24.

26. Kassif Y, Rehany U, David M, Popko A, Rumelt S. The course of epiphora after failure of silicone intubation for congenital nasolacrimal duct obstruction. Graefe's Arch Clin Exp Ophthalmol. 2005; 243:758. doi:10.1007/s00417-004-1115-4.

27. At Tarzadeh Ab, Sajjadi M, Owji N, Reza Talebnejad M, $\mathrm{Fa}$ Rvardin M. Inferior turbinate fracture and congenital nasolacrimal duct obstruction. European Journal of Ophthalmology. 2006; 4:520-524.

28. Katowitz JA, Welsh MG. Timing of initial probing and irrigation in congenital nasolacrimal duct obstruction. Ophthalmology. 1987; 94:698-705.

29. Havins WE, Wilkins RB. A useful alternative to silicone intubation in congenital nasolacrimal duct obstructions. Ophthalmic Surg. 1983; 14:666-70.

30. Pediatric Eye Disease Investigator Group. Balloon Catheter Dilation and Nasolacrimal Intubation for Treatment of Nasolacrimal Duct Obstruction Following a Failed Probing. Archives of Ophthalmology. 2009; 127(5):633-639. doi:10.1001/archophthalmol.2009.66.

31. $\mathrm{Hu} \mathrm{M}, \mathrm{Wu} \mathrm{Q}$, Fan $\mathrm{YW}, \mathrm{Cao} \mathrm{WW}$, Lin $\mathrm{Q}, \mathrm{Yu} \mathrm{G}$. Comparison of balloon catheter dilatation and silicon intubation as the secondary treatment for congenital nasolacrimal duct obstruction after failed primary probing. Zhonghua Yan Ke Za Zhi. 2016; 52(2):123-8. doi: 10.3760/cma.j.issn.0412-4081.2016.02.009.

32. Yu G, Hu M, Wu Q, Cao WH, Fan YW, Lin Q, Liu W. Balloon dacryocystoplasty in the treatment of congenital nasolacrimal duct obstruction after previous unsuccessful surgery. Zhonghua Yan Ke Za Zhi. 2011; 47(8):698-702.

33. Korkmaz H, Korkmaz M, Karakahya RH, Serhatlı M. Endoscopic intranasal surgery for congenital nasolacrimal duct obstruction-a new approach. Int. J. Pediatr. Otorhinolaryngol. 2013; 77(6):918-21. doi: 10.1016/j.ijporl.2013.03.005.

34. Hartikainen J, Grenman R, Puukka P, Seppa H. Prospective randomized comparison of external dacryocystorhinostomy and endonasal laser dacryocystorhinostomy. Ophthalmology. 1998; 105:1106-1113. 
35. Cokkeser Y, Evereklioglu C, Er H. Comparative external versus endoscopic dacryocystorhinostorny: results in 115 patients (130 eyes). Otolaryngology Head and Neck Surgery. 2000; 123(4):488-491.

36. Vivek KP, Debajit D, Uttal TB, Pinpo T. A Comparative Study between Conventional and Endoscopic Dacryocystorhinostomy. IOSR-JDMS. 2013; 6(2):38-40.

37. Dey AK, Gayen GC, Jana S, Ghorai S, Sarkar A, Ganguly P. External and Endoscopic Dacryocystorhinostomy in Nasolacrimal Duct Obstruction: A Comparative Study. IJHSR. 2014; 4(12):115-120.

38. Choung HK, Khwarg SI. Selective non-intubation of a silicone tube in external dacryocystorhinostomy. Acta Ophthalmologica Scandinavica. 2007; 85:329-332. doi:10.1111/j.1600-0420.2006.00827.x.

39. Pakdel F. Silicone Intubation Does not Improve the Success of Dacryocystorhinostomy in Primary Acquired Nasolacrimal Duct Obstruction. Journal of Ophthalmic \& Vision Research. 2012; 7(3):271-272.

40. Kamal S, Ali MJ, Naik MN. Circumostial injection of mitomycin C (COS-MMC) in external and endoscopic dacryocystorhinostomy: efficacy, safety profile, and outcomes. Ophthal. Plast. Reconstr. Surg. 2014; 30(2):187-90. doi: 10.1097/IOP.0000000000000102. 